CASE REPORTS

\title{
IgA abnormalities in Mediterranean lymphoma (alpha chain disease)
}

\author{
S. N. Salem \\ D. Phil. (Oxon), F.R.C.P.E. \\ Gastroenterology Research Unit, Sabah Hospital \\ B. LAZAROV
M.D.
}

Pathology Department, Sabah Hospital

\author{
M. W. KanAN \\ M.R.C.P. (Lond., Glas.) \\ Pathology Department, Sabah Hospital \\ Y. T. OMAR \\ F.F.R.
}

Radiotherapy Department, Sabah Hospital

\author{
H. Al-Awady \\ F.R.C.S. (Lond., Edin.)
}

Surgical Department, Emerie Hospital, Kuwait, Arabia

Proliferative diseases associated with dysproteinaemia include multiple myeloma, primary macroglobulinaemia of Waldenström (1958) and gamma heavy chain disease (Franklin et al., 1964).

Rambaud et al. (1968) added a new entity, alpha chain disease, to the group when they identified a heavy chain polypeptide (IgA) in the serum and urine of a young Syrian female patient with 'Mediterranean' abdominal lymphoma and malabsorption. Four further patients, three Algerian Arabs and one Eurasian were reported to have the same clinical and laboratory findings (Seligmann et al., 1969).

In this communication we wish to report the first case of alpha chain disease, in a Lebanese Arab girl, encountered in Kuwait, Arabia.

\section{Case report}

F.A.A., a 17-year-old girl, was referred to us in March 1970, complaining of diarrhoea, loss of weight, shortness of breath, palpitation, abdominal distension, fever and bouts of diffuse abdominal pain. The symptoms started insidiously 3 months prior to the time of consultation. As her diarrhoea had progressed, with poor appetite, she lost $12 \mathrm{~kg}$ over the previous 3 months. There was no history of past illnesses. The patient was the second child of Arab Lebanese parents who have another nine healthy children, all being resident in Kuwait for the last 6 years.

On examination she looked pale, emaciated and dyspnoeic, her weight was $38 \mathrm{~kg}$, height $150 \mathrm{~cm}$, temperature $38 \cdot 4^{\circ} \mathrm{C}$, pulse $122 / \mathrm{min}$. The head, neck, lungs and heart were normal. The abdomen was distended, the liver was enlarged one finger breadth below the right costal margin and was firm in consistency. There were hard, mobile and tender masses felt around the umbilicus with easily palpated loops of small intestine. There was no peripheral lymphnode enlargement. The CNS, skin and joints were normal.

\section{Investigations}

Stools were positive for occult blood, no ova or parasites were detected and stool culture was negative for salmonellosis and shigellosis. Urine examination revealed no albuminuria or Bence-Jones proteinuria. $\mathrm{Hb}, 55-70 \%$; WBC, $4000-10,000 / \mathrm{mm}^{3}$, lymphocytes predominating; ESR, 125-148 mm/first $\mathrm{hr}$; bone marrow aspirate showed a normal picture. Liver function tests revealed no abnormalities except for a low prothrombin activity value $(64 \%$ of the control).

Sigmoidoscopy revealed normal appearance of colonic mucosa. X-ray of the chest showed clear lung fields with normal heart size and shape. Barium follow-through: gross abnormality of the small intestine giving the picture of malabsorption syndrome.

Peroral jejunal biopsy revealed flat mucosa, severe villous atrophy and heavy infiltration with plasma cells suggestive of coeliac disease. $5 \mathrm{~g}$ Dxylose absorption excretion test shows impaired 
absorption $(0.5 \mathrm{~g}, 10 \%$ excreted). A diagnosis of adult coeliac disease was made and the patient was put on a gluten-free diet, antibiotics and antidiarrhoea agents with supportive measures but with no response.

During the course of investigation, communication with Professor Rambaud of Saint Lazare Hospital, Paris, and with Professor Seligmann of SaintLouis Hospital, Paris, took place and the patient's serum was studied by them for abnormal globulins. They found that the precipitation line of alpha chain disease was easily seen on the immunoelectrophoresis done with a polyvalent antiserum strengthened by anti IgA antibodies, labelled by an arrow (Fig. 1).

On the 12 November 1970 she developed a picture of what seemed to be a small intestinal obstruction for which laparotomy was performed on 15 November 1970. There was no fluid collection in the peritoneal cavity but there was extensive enlargement of all mesenteric lymph-nodes. There was no evidence of intestinal obstruction.

Biopsies were obtained from mesenteric lymphnodes, jejunum and the liver. Histological examination of biopsy materials revealed the following findings: Jejunal biopsy showed partial villous atrophy in some areas and severe villous atrophy in other areas. Very few glandular crypts were preserved in the section. The lamina propria was infiltrated by mature typical plasma cells and very few lymphocytes. A few plasma cells were binucleated but did not show any sign of atypicality or malignancy. Sections from the lymph-node biopsy showed destruction of the whole architecture by dense proliferation of typical plasma cells and a few lymphocytes. Sections from the liver showed cloudy swelling and fatty degeneration of the hepatocytes (Fig. 2). The periportal tracts were infiltrated by plasma cells, a few histiocytes and lymphocytes. Dr A. Galian, of Laboratoire Louis Fruhling, Paris, through the courtesy of Professor Rambaud, examined the sections and confirmed our histopathological findings and thought they were compatible with those of 'Mediterranean' lymphoma.

\section{Management and follow-up}

On 10 December 1970, the patient was started on a combined course of Endoxan and vinblastin (total dose of $6 \mathrm{~g}$ and $24 \mathrm{mg}$ respectively). Until regression of abdominal masses was noticed she stayed in a remission on $4 \mathrm{mg}$ vinblastin weekly until 16 February when she started to complain of vomiting

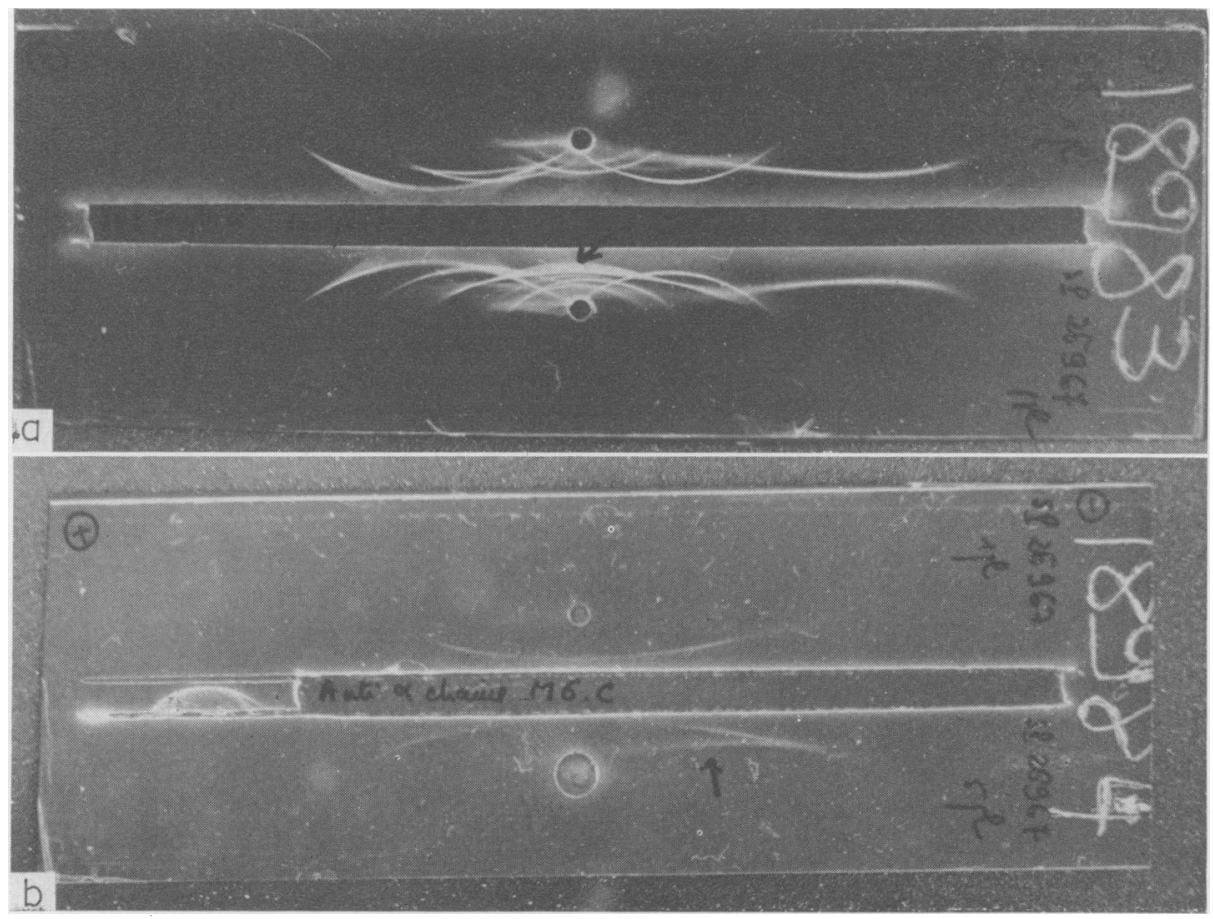

FIG. 1. Immunoelectrophoresis. The precipitation lines of alpha chain disease are indicated by arrows in (a) and (b). 


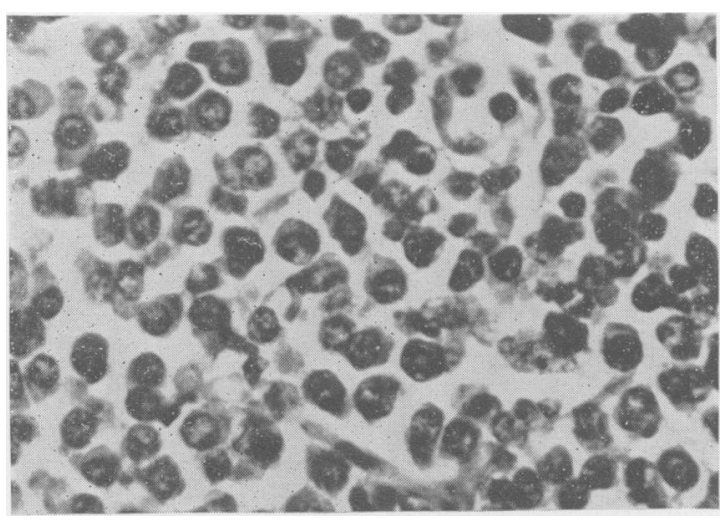

FIG. 2. Marked lymphoid proliferation in periportal space and amongst adjacent hepatocytes which show fatty degeneration. $\mathrm{H}$ and $\mathrm{E}, \times 96$.

and diarrhoea. Examination revealed grossly enlarged abdominal masses. By then the diagnosis of Mediterranean lymphoma (alpha chain disease) was confirmed by Professor Rambaud and colleagues (1970). Telecobalt irradiation was decided and a total abdominal dose of 3000 rads were delivered over 5 weeks which resulted in considerable regression of the masses.

On 12 April 1971 she developed cervical lymph node enlargement which regressed on $100 \mathrm{mg}$ daily of Endoxan. On 25 May the patient left to Beirut, Lebanon for convalescence. Two weeks later, she developed continued high fever, marked neck swelling and abdominal distension with vomiting and diarrhoea, for which she was admitted to AUB Hospital (American University of Beirut). Unfortunately she expired on 21 June after 10 days of admission. However, the parents refused permission for necropsy.

\section{Discussion}

The clinicopathological findings and the serum immunoglobulin abnormality in our patient are consistent with those previously reported in welldocumented cases of 'Mediterranean' lymphoma or alpha chain disease (Rambaud et al., 1970). The disease is characterized by a diffuse lymphoid cell proliferation of the lamina propria of the small intestine and the mesenteric lymph-nodes causing severe malabsorption and also by the presence in the serum and urine of a polypeptide representing a fragment of the alpha chain of IgA immunoglobulin (Rambaud et al., 1968, Seligmann et al., 1968, Seligmann \& Rambaud, 1969)

With the exception of a 25-year-old Eurasion man (Rambaud et al., 1970) all the patients hitherto reported with this syndrome were either of Arab or
non-Ashkenazi Jewish stock (Eidelmann, Parkins \& Rubin, 1966, Seligmann et al., 1968; Seligmann \& Rambaud, 1969). The Eurasian case threw some doubt on the previous impression by these authors, of a selective racial predisposition to this syndrome. However, in view of its frequent occurrence in Mediterranean people, some authors tried to speculate on the possible role of ethnic, geographical and environmental factors such as dietary, bacterial and parasitic infections in the genesis of this abdominal lymphoma (Eidelmann et al., 1966).

The main clinical presentation had always been in the form of severe progressive malabsorption with its known sequelae and complications. The diarrhoea did not usually respond to a gluten-free diet, antiinfective or antidiarrhoeal drugs. In previous reports the disease was always confined to the abdomen whereas in our patient enlargement of cervical lymph-nodes occurred in the later stages. In the serum of four well-investigated patients (Seligmann \& Rambaud, 1969) significant immunoglobulin abnormalities were detected. In two patients, the serum electrophoretic pattern revealed a broad band extending from alpha-2-beta-2 globulins, a decrease in serum albumin, possibly due to severe intestinal malabsorption, and a profound hypogammaglobulinaemia. Immunoelectrophoretic analysis with polyvalent antisera to normal whole human serum revealed an abnormal precipitin line extending from alpha-1 globulin to the slow beta-2 region, crossing at its extremities the serum albumin and gamma-G lines. The pathological proteins of all four patients belonged to the alpha-1 subclass. This protein did not precipitate with any antiserum specific for $\alpha$ or $\lambda$ light chains. Identical findings were obtained in the urine of these patients.

Small intestinal biopsies showed massive proliferation of lymphoid cells in the lamina propria with secondary villous atrophy and few crypts. Proliferating cells were pleomorphic with plasma cells predominating. However, malignant cytological features were found in one case only.

Mesenteric lymph-nodes showed necrosis and a pattern compatible with the diagnosis of plasmacytosarcoma in one case and of reticulum cell sarcoma in another. Other lymphoid organs almost always escaped (Seligmann \& Rambaud, 1969). Our case, however, seems to be the first in the literature to exhibit involvement of the liver mainly in the periportal spaces and to a lesser extent amongst the hepatocytes (Rambaud, 1971). On the other hand, electron microscopic study of intestinal biopsies from two patients showed the proliferating cells to have the same morphologic features of plasma cells observed in typical multiple myeloma, in some forms of Waldenström's macroglobulinaemia (Dutcher \& Fahey, 1959; Besis, Breton-Gorius \& Binet, 1963) 
and in a case of plasmacytic reticulium cell sarcoma (Okano, Azar \& Osserman, 1966).

The course of the disease seems to be progressive inspite of temporary response, reported in a few cases, to cytotoxic drugs and systemic coticosteroids. In our case, the course of the disease took about 18 months from the time she developed symptoms until she died.

In conclusion, the differential diagnosis of alpha chain disease from other malignant lymphomas that may involve the small intestine and other proliferative syndromes with dysproteinaemia appears to depend on the identification of heavy alpha chain polypeptide $(\operatorname{IgA})$ in the serum and urine together with other clinical and pathological characteristics.

\section{Acknowledgment}

We would like to thank Professor J. C. Rambaud, Professor M. Seligmann and Dr A. Galian of Paris for conducting serum electrophoresis, checking up the histological materials and for their constructive correspondence. Our thanks are also due to Dr Adnan Rayis for referring the patient.

\section{References}

Besis, M.C., Breton-Gorius, J. \& Binet, J.L. (1963) Etude comparée du plasmocytomie et du syndrome de Waldenstrom. Nouvelle revue française d'hématologie, 3, 159.
Dutcher, T.F. \& FAHEY, J.L. (1959) The histopathology of the macroglubulinemia of Waldenstrom. Journal of the National Cancer Institute, 22, 887.

Eidelman, S., Parkins, J.J. \& Rubin, C.E. (1966) Abdominal lymphoma presenting as malabsorption. A clinicopathological study of nine cases in Israel and review of the literature. Medicine, 45, 111.

Franklin, E.C., Lowenstein, J., Bigelow, B. \& Meltzer, M. (1964) Heavy chain disease, a new disorder of serum Y-globulins. Report of the first case. American Journal of Medicine, 37, 332.

Okano, H., Azar, H.A. \& Osserman, E.F. (1966) Plasmacytic reticulum cell sarcoma, case report with electron microscopic studies. American Journal of Clinical Pathology, 46, 546.

Rambaud, J.C., Bognel, C., Prost, A., Bernier, J.J., Le Quintrec, Y., Lambling, A., Danon, F., Hurez, D. \& SeligmanN, M. (1968) Clinico pathological study of a patient with mediterranean type of abdominal lymphoma and a new type of IgA abnormality 'alpha chain disease'. Digestion, 1, 321.

Rambaud, J.C., Matuchansky, C., Bognel, J.C., Bognel, C., Bernier, J.J., Scotto, J., Perol, C., Ferrier, J.P., Milaesco, E., Hurez, D. \& SeligmanN, M. (1970) Nouveau cas de maladie des chaines alpha chez un Eurasien. Annales médicine interne, 121, 135.

Seligmann, M., Mehaesco, E., Hurez, D., Mehaesco, C., Preud'homme, J.L. \& Rambaud, J.C. (1969) Immunochemical studies in four cases of alpha chain disease. Journal of Clinical Investigations, 48, 2374.

Seligmann, M. \& Rambaud, J.C. (1969) IgA abnormalities in abdominal lymphoma ( $\alpha$-chain disease). Israel Journal of Medical Sciences, 5, 151.

WALDENSTROM, J. (1958) Die Macroglobulinaemia Ergebn-in. Med. U. Kinderh, 9, 586.

\title{
Precocious sexual development in an untreated cretin
}

\author{
D. T. D. BulugahapitiYa \\ M.B., B.S.(Cey.), M.R.C.P., M.R.C.P.(Glas.), D.C.H. \\ Government Hospital Gampaha, Ceylon
}

\begin{abstract}
UNTREATED hypothyroidism usually results in retardation of physical and mental development. Sexual development too is retarded and corresponds approximately to the bone age. Rarely, however, thyroid deficiency in childhood may be associated with precocious sexual development. Bergstrand (1955) and Silver (1958) described girls with juvenile hypothyroidism who had precocious menstruation and other signs of sexual development. Van Wyk \& Grumbach (1960) reported three girls with juvenile hypothyroidism, breast enlargement, galactorrhoea and early menstruation. Kendle (1905) described an untreated cretin with precocious puberty.
\end{abstract}

The case reported here is a 10 -year-old untreated cretin with precocious sexual development.

\section{Case report}

A.R.C. (date of birth: 7.10.60) was admitted to hospital on 4 February 1971 with a history of lower abdominal pain and vaginal bleeding of 6 days' duration. There was no history of headache, fever or vomiting.

Vaginal bleeding had also occurred at 5 years and $7 \frac{1}{2}$ years of age lasting 4 days and 6 days respectively. The patient is the last in a family of six. Her parents are first cousins. An elder sister of the patient has a 